\title{
SUBSTANCE USE IN PERFORMING ARTISTS: EXPLORING LINKS TO CREATIVITY AND PERFORMANCE
}

\author{
Bani Khurana ${ }^{1}$ and Amrita Joshi ${ }^{2}$ \\ ${ }^{1}$ Applied Psychology with specialization in Counselling Psychology, Tata Institute of Social Sciences, Mumbai \\ ${ }^{2}$ School of Human Ecology, Tata Institute of Social Sciences, Mumbai
}

\begin{abstract}
The paper aimed at assessing attitudes of performing artists in India towards use of substances and current status of substance use prevalent amongst them. Their perceived reasons for the usage were explored along with their beliefs towards the effects of substances on creativity and performance. Non- probabilistic sampling was used to collect data from 77 artists through a self -developed quantitative questionnaire and 10 in depth interviews of artists in the age range of 18-35 years were taken. The quantitative data was analyzed by calculating descriptive and inferential statistics. The findings were then supported by the themes emerging from the qualitative interviews. Results indicated a positive expectancy of using substances in the field of performing arts, especially related to stress relief, loss of inhibitions, increasing energy and experiencing the character more fully. A subjective increase in creativity was reported by majority of the sample. Substances were reported to be acceptable in the industry for the purposes of networking and leisure. Commonly reported factors for initiation of usage were curiosity and experimentation which have been stated in literature, while specific reported factors maintained the usage such as coping with physical and emotional strain, hectic schedules, lack of support from family and financial and occupational instability. There is potential for research on the grounds of establishing statistical associations between substance use, creativity and performance. Issues faced by Indian performing artists triggering and maintaining substance use and abuse could be further explored in depth.
\end{abstract}

Keywords: Substance use, Performing Artists, Creativity, Addiction

\section{INTRODUCTION}

To define a psychoactive substance various properties such as an external dose with a chemical base directly affecting the central nervous system, altering brain functioning which results in temporary behavioural changes, along with changes in perceptions, consciousness and mood of the individual, is necessary.

Research shows that the active agents of substances were not extracted till 19th century A.D. Earlier, physicians often prescribed drugs such as Morphine for its effects on relieving pain. Eventually these prescriptions initiated the cycle of unregulated peddling of drugs by various sources, local and overseas. Morphine was one of the most common drugs used to cure war veterans in the American Civil
War, resulting in them returning home with their kits with this drug and hypodermic needles. Opium was another popular drug in the 1900's. It was estimated that by early part of this century, there were nearly 250,000 addicts in the United States of America.

Various drugs have found their prevalence in the Indian subcontinent by their extensive mention in various Hindu Texts and scriptures. They are linked to pious usage and Hindu deities, prescribed and fed through cultural beliefs. The earliest known consumption of any kind of substance is dated back to 2000B.C (somras/sura). Indian texts considered these as well as cannabis as source of happiness and liberators. These also have a history of being given to oxen by farmers to build strength to plough their 
fields. Used by many sadhus and aesthetics these for their unique properties, these also produce hallucinations and timelessness. Bhang drinking (cannabis) is a part of various social and religious customs in India, as taken to celebrate on the festival of Holi. Opium was used habitually during the moghul period, later replaced by smoking in M.P, U.P. and Rajasthan (Ganguly, 1995).

The World Health Organization defines substance abuse as persistent or sporadic drug use inconsistent with or unrelated to acceptable medical practice.

\section{Documented Substance use in Western Culture}

The outlaw of opium dens in San Fransisco first happened in 1875. In 1906, the National Drug Law was passed. This also led to the Harrison Narcotic Act in 1914 to curb the sale of opium and cocaine. Heroin faced a legal ban at this stage. The Supreme Court also made it illegal for doctors to prescribe any narcotic drugs to addicts. Due to all these measures there was a decrease in the use of narcotics across the country. The 1950s, saw a massive increase in the use of marijuana, amphetamines and tranquilizers. In 1980s, cocaine and crack use again soared.

By the 1970's some localities had decriminalized the use of various narcotics and the drinking ages had also gone down in many states of the United States of America.

\section{Documented Substance use in Indian Culture}

Opium has been under the Central Government Monopoly since 1857 . The prohibition of Opium was seen throughout India's Independence movement. 1611 opium smokers were reported in the country with $1 \%$ found to be addicted to cannabis (Chopra \& Chopra, 1965).

With a vast population of more than 1 billion, research shows that about 3 million people are suffering from drug addiction in India. According to a survey by the World Health Organization, Cannabis, Heroin, Opium and Hashish, along with cigarettes are the most common substances used in India. An increasing upsurge of methamphetamine users is also seen. Analgesic intravenous injections like dextropropoxphene are reported from many states, due to its easy accessibility at 1/10th the cost of heroin. Codeine-based cough syrups are diverted from the domestic market for abuse.

The prevalence rates according to recent studies are 0.94 to 13 per 1000, in Uttar Pradesh 18.55-22.8 per 1000. In a 1998 study by Chandrashekhar \& Reddy the prevalence rate of alcohol/drug use was found to be 6.9 per 1000 in the Indian population. Another recent study in Lucknow revealed that regular users constituted of $73.65 \%$ tobacco smokers, $62.38 \%$ were experimenting alcohol and $64.28 \%$ of psychotropic drug users were dependent.

The Narcotic Drug and Substances Act was introduced in 1985 which made it illegal for a person to produce/manufacture/cultivate, sell, transport, consume, possess, purchase or / and store any psychotropic substance. There have been various amendments to the act in 1998, 2001 and recently in 2014.

\section{Drug use and Creativity}

The use of psychoactive substances has been commonly linked to creative outcomes and expectancies.

Though there have been inconclusive studies on the effects of substances on creativity. Alcohol has been associated to increase creativity by reducing inhibitions, as supported by the dis-inhibition hypothesis. Nicotine has been linked to cognitive gains such as information processing, working memory function and speed, while negligible effects on creativity were seen. (Runco \& Pritzker, 2011).

In a study done on Cognitive Motivations for Drug use it was found that enhancing positive affect and creativity was seen as one of the major factors for the 15 reasons for drug use. A longitudinal analysis over a span of 1 year showed that actual alcohol use increased with the motivations of using alcohol while motivations to use cannabis also increase the use of other drugs (Newcomb, Chou, Chih-ping, Bentler\&Huba,1988).A study done by Hicks, Pederson, Friedman \&McCarthy,2011 tested the creative performance of 566 substance related primes possessing creativity related substance expectancies. Two different groups were exposed to alcohol and marijuana respectively and were then given a creative problem solving task and a divergent thinking task in 
the same order. The results showed that an exposure to the psychoactive substance enhanced performance on creativity tasks for those who expected that the substance would enhance creative functioning while this same result was not seen on measures unrelated to creative problem solving, clearly indicating that creativity related expectancies influenced creative performance.

\section{Performing Arts}

Performing art is defined as a live genre of art forms wherein an expression of aesthetic and artistic capabilities is done in front of an audience using paths like movement, voice, body, etc. it is very different from the visual arts in which the artist creates physical art objects, working in isolation.Media played an important role in the dissemination of performances by using film and video recording. Yet these practices were well established on ritualistic grounds for many years, to be performed live, in front of an audience. The development of this into a structured art form with an emphasis on challenging the conventional notions of art and concept exploration, through people and artists as intermediaries.

Performing arts can be categorized into various fields, the more primary or popular forms being, dance, music, theatre and musical theatre. The secondary or minor forms include mime, magic or illusion, puppetry/circus arts, spoken word, public speaking and recitation.

\section{Performing arts in India}

Natyashastra, first written in the 2nd century had laid the foundation for dance, drama and music in the Indian context. The navaras including love, pathos, heroism, humour, terror, wonder, disgust, serenity and anger, form the crux to Indian aesthetics.

Classical music has always been regarded as a form of meditation, concentration and worship. Indian Music constitutes of two integral variants -the Raga, musical mode and the Taal. The Bhakti traditions introduced two types of classical music, Carnatic (southern Indian) and Hindustani (northern Indian), after the 5 th century.
The six most popular Classical dances prevalent in India are; Manipuri, Kathak, Odissi, Bharatanatyam, Mohiniattam and Kathakali.

Theatre (drama) has a rich tradition in India for over a thousand years. It is still popular in various cities yet is struggling since the arrival of television and movies.

Performing arts has always been seen as a form of entertainment in India. The occurrence of professional training in stage art forms is a recent phenomenon. It is still to be fully recognized as an individual and independent source of income, falling prey to various notions attached to its novel formation and challenging the popular fields of economics and trade.

The life of these performers are full of extremities, facing problems of unemployment, time and money along with severe practice schedules, causing a vulnerability to various musculoskeletal injuries, sacrificing on personal lives and simultaneously creating something new for the stage, facing criticism and rejection consistently. These are yet added by the increased amount of stress, persistent in this profession due to the above mentioned difficulties.

According to a study by Wanke, Arendt, Mill, Koch, , Fischer, Groneberg in 2014 , Stage performances seem to carry an increased injury risk compared to rehearsals. The "risk" of on-stage work is spread across various factors that seem to be stagespecific. Injuries were most commonly caused by the "partner" (21.7\%) or "floor" (21.0\%). The lower extremity was the most commonly affected body region $(63.6 \%) \quad(\mathrm{p}<0.001)$. Most $(79.4 \%)$ of the accidents on stage occurred during an ongoing performance (frequency: 10.1/100 performances), with only $19.7 \%$ occurring during rehearsals on stage ( $p<0.001)$. Due to the sustained injury, $30.2 \%$ of the dancers sustained a time-loss injury.

Another study on Occupational Stress and Coping Strategies of Professional Ballet Dancers in Korea by Noh, Morris, \& Andersen, 2009 found by using Inductive content analysis of the data identified four major sources of stress: physical (i.e., physical appearance, poor physical condition), psychological (i.e., desire, slump, personality), interpersonal (i.e., relationship with a dance director, relationship with 
other dancers), and situational factors (i.e., performance demands, finances). The results demonstrated that, within physical factors, physical appearance (e.g., maintaining a particular body type, keeping low body weight) was a preeminent problem.

Difficulties faced by performing artists could serve as factors for use of substances for various reasons such as stress reduction and coping. This makes them a vulnerable population for the effects of addiction commonly associated with substance use and abuse for various reasons. The various activities which could contribute, such as:

- $\quad$ Frequent shows
- $\quad$ Tiring tours
Handling the media
- $\quad$ Auditions
- Connections to drugs and alcohol from
friends or co-worker

\section{Drugs and its Effects}

Psychoactive substances often bring about subjective (although these may be objectively observed) changes in consciousness and mood that the user may find pleasant (e.g. euphoria) or advantageous (e.g. increased alertness) and are thus reinforcing.

Martin Barnes \& Professor David Nutt explain the results of research into the effects of recreational drugs on the brain. (2013)

Acid (LSD) and magic mushrooms. These have hallucinogen properties and make people experience the surroundings in a different 'trippy' way.

Cannabis (marijuana, weed, dope, skunk)These have a relaxing effects on people. It also has effects on memory and may make them forget things.

Cocaine and crack cocaineIt is a stimulant which makes a person feel confident and full of energy.
Ecstasy (E) It is a hallucinogen stimulant that makes a person feel high, increases energy and gives a carefree and happy feeling.

Heroin (smack, diamorphine)This along with other opiates slow down a person's functioning and curbs emotional and physical distress.

Ketamine (K) This is an anaesthetic drug which gives a relaxed and calm feeling with unpredictable effects. Loss of control over behaviour, engagement in impulsive and reckless behaviour along with hyperthermia are reported effects. (Nutt, 2013). It can make you feel detached from yourself and others.

Solvents (gases, glues and aerosols)These give a drunken feeling along with hallucinations.

Speed and crystal meth (amphetamine and methamphetamine)It is known to increase energy and confidence quickly but may also cause paranoia and irritability. A variant of speed methamphetamine (crystal meth) can bout high fever with feelings of hopelessness, when it wears off.

Steroidspump up muscle mass but can bring on 'roid rage.

Valium (tranquillizers, benzodiazepines) Tranquillizers such as valium are sedative drugs that relieve anxiety and make people feel calm and relaxed. It is also used to wear off cocaine and speed effects.

The dynamic performing arts field requires a great amount of resilience in the professionals. "People in such a high pressure profession are under constant scrutiny and tend to develop issues with depression and anxiety, and, sadly, they abuse substances as a coping skill," (Alonso, 2013). Being in a profession like the literary arts or performing arts is a risk factor for Substance abuse and addiction. When an artist is trying to build a following, her schedule could become so tight that the very much needed periods of rest become almost non-existent. It is easy to see, then, why a drug prescribed to treat anxiety could be alluring (Khantzian\&Albanese, 2008).

Performing artistes need to possess various characteristics such as creativity, spontaneity, endurance, skill establishment, technique 
enhancement, etc. Though previously inconclusive results have been found on the link between creativity and substance use, some supporting studies and linkages have been confirmed. As reported as the disinhibition hypothesis, substances help in losing inhibitions, thus improving performances and surpassing mental blocks in artists.

Marijuana help in increasing originality and authenticity, in result helping in innovation and formation of new choreographic routines, scripting, thinking about new tricks and helps in discovering new associations, to present to an audience in an entertaining form. Also musicians are reported as high users of various illicit drugs, than the general population (Pritzker, 1999)

Yet, contrastingly, Kerr , Shaffer, Chambers \& Hallowell(1991) found a lack of significant differences in the use of various illegal drugs when comparing, artists, composers and argued that many creative individuals described the experience of initially perceiving substances as useful to creativity only to find them destructive in the long run.

Janiger and De Rios(1989) investigated 20 artistes' work before and after administration of LSD. The findings were not clear at to if the individual artist was able to produce aesthetically superior work during the period when the drug was operable

Other studies such as Lowe(1995) found significant positive correlation between the creativity of 619 people and their degree of substance use. Steffenhagen, McCann \&McAree(1976) found that drug users scored higher than non-drug users on two tests of creativity.

Goldstein and Eisenman(1974) found positive correlation between the characteristic of adventuresomeness and risk taking with increased use of substances. Gordon(1999) also explored in his study about how musical hallucinations(induced by illegal drug use- LSD) could be a source of artistic creativity for music composers.

An unpublished study by North and Beauvois obtained complete set of lyrics and dates of drug usage for 5 well known pop groups/artists(namely Aerosmith, The Rolling Stones, The Incredible String Band,The Beatles and the Todd Rundgren.) .
Computer analysis of the lyrics indicated that measures of lyrical aggression increased after periods of drug usage, whereas levels of ambivalence, cognitive terms and cooperation decreased after such periods.

Further more,in a longitudinal study of Comparative analysis of substance use in ballet, dance sport, and synchronized swimming done by, Peric , Zubcevic\&Ostojic , 2010 , Using the Kruskal-Wallis test, they found no significant differences, between the groups taken for the study in terms of behaviours related to doping. Most of the examinees reported that they did not rely on physicians' and/or coaches' opinions regarding these behaviours. Only sport dancers admitted consumption of cannabis as antidoing rules violation. Artists more convinced and recognizing that these kind of habits exist in their sport (or art) have a certain tendency toward doping usage.

Another study done by Sekulic ,Peric\&Rodek, 2010, on Substance use and misuse among professional ballet dancers investigated substance use and misuse among 16 female and 9 male Croatian ballet professionals in 2008 using an original questionnaire. Analysis of personal, educational factors, activity and training related and social factors and other criteria such as: appetite suppressant, binge alcohol drinking, analgesic use, cigarette smoking and actual and potential "doping" habits. More than one third of the male dancers reported binge drinking, while $20 \%$ of the females smoked more than a box of cigarettes per day. Almost 25\% of these dancers will use "doping" if it will ensure successful ballet performance, even if negative health consequences are faced. In males, the risk of potential "doping" behaviour increased with age. In females, a negative correlation was found between education level and cigarette smoking, but positive correlation was found between potential "doping" habits and behaviour.

A study done by Sekulic, Kostic\&Miletic in June, 2008 focused on Substance Use in Dance Sport. In which they analysed SU and factors related to SU in dance sport. The sample subjects comprised of 21 female and 22 male dancers, all >19 years of age, who were given an anonymous questionnaire developed for this study. The results found that alcohol consumption was common but not frequent in 
more experienced and successful dancers. Pain killer usage related to age in female dancers (all at $\mathrm{p}<$ $0.05)$.

This study pertains to explore the current usage of substances in professional performing artists as well as their perceived link between substance use, creativity and performance. As with huge gaps in literature and various inconclusive results, it is an attempt to discover novel associations in this area, in the Indian Context. The study also assesses how attitudes towards the use of substances in the field of performing arts along with perceived links to performance and creativity of artists can lead to an increased use of substances among them, making them vulnerable to substance addiction. The findings would thus, enable us to communicate the actual effects of substances on their physical health and form a base for finding the true connection between substance use and creative expression. It will also set a ground for further exploration in the fields of creativity, drug use and performance enhancement among artists.

\section{METHODS}

The current study looked at the pattern of Substance Use in performing artists. The main objectives of the study were as follows:

\section{OBJECTIVES}

1. Attitudes towards substance use in the sample.

Domains:

- General attitudes towards substance use

- $\quad$ Perceived link between substance use and creativity

- Perceived reasons and subsequent patterns

2. To explore the current usage and prevalence of substance use in professional performing artists.

Various researches have shown that performing artists face a lot of unique stressors. Social anxiety is noted as one of the main reasons for substance use in this field. Various illicit drugs also act as esteem boosters as well as performance enhancers and hence, these objectives were made to explore these particular aspects.

\section{Research Design}

An Exploratory research design with a mixed method approach was applied to collect data for the current study.

\section{Research Tools}

To pertain to the quantitative part, a self-constructed questionnaire was developed which comprised of 46 questions. A parallel qualitative analysis was done of 10 personal interviews conducted on professional performing artists, trained in any form of performing art and currently engaged in stage performances. The quantitative questionnaire had objective type questions corroborated with open ended, descriptive questions, to understand each respondent's idiosyncratic meaning. The personal interview was based on the participant's experiences of using substances and its effect, if any, on their individual understanding of creativity and performance in their profession. The interview focused on asking open ended questions about their attitudes towards substance use in professional performing artists, their various reasons for usage, pertaining to this profession and the consequences of using any kind of psychoactive substance with proximity to performance on stage, also assessing creativity as regarded in their professional environment, and the use of substances. Triangulation of methods was used to corroborate the data collected with consideration to the objectives.

\section{Sampling}

Snowball and purposive non probability sampling technique was used. As the target population was difficult to access and was mostly done by freelancers in the performing arts industry and their further contacts, these techniques of sampling were decided upon, to make the study feasible. 


\section{Participants}

The sample was decided to include people who were within the age range of 18 - 35 years and were currently professionally engaged in the field of performing arts. The criteria set to define the population was that the participants must have been trained in any one form of performing art for minimum 6 months and should have done at least one stage performance, including an audience.Here performing art would include fields like dance, music, theatre, gymnastics, magic and trickery. The data was collected from 86 people, with 76 quantitative questionnaires and 10 personal interviews. The data was collected from one theatre institute, one performing arts academy and individual freelancing performing artists.

Visual artists were excluded from the study as most of them engage in art work individually, without an audience and hence an important aspect of stage performance would not be assessed.

\section{Data Collection}

The data was collected in Mumbai and Delhi, India. A consent form was attached with each copy of the questionnaire. Freelance performing artists were contacted for the data collection. Permission was also obtained from a theatre institute and performing arts academy, to collect data from the students.

The researcher was present at the time of data collection. The consent form was mandatory to be signed by the participants. It contained a brief about the study and the clauses of anonymity and confidentiality on the part of the researcher and the participant were explained.

All the questions of the respondents were answered and the queries were addressed. The respondents were debriefed about the details of the study and how the results will be used.

\section{Data Analysis}

Data was analysed using descriptive analyses. Means, frequencies, percentages and averages were computed.

\section{RESULTS}

\section{Attitudes towards Substance Use}

A majority percentage of individuals (44\%) within the chosen population agree that some substances help in increasing their imagination and creativity. $41 \%$ also agree that substances may help them or someone in facing an audience. These findings indicate a more favourable way of perceiving substances vis-à-vis performance.

Among the participants 54\% had been offered to use substances by their colleagues, co-performers, mangers, in their professional environment. This finding hints at the possible frequent usage among performing artists and the normalization of Substance Use in the field.

Majority percentage of individuals in the representing sample, disagree with items which ask about a substances effect on sleep, pain and thinking.

It suggests that more than eliminating negative consequences, providing positive effects are the more preferred benefits of using Substances.

$51 \%$ of women and $60 \%$ of men agree that substances may somewhere help them in decreasing physical pain. $48 \%$ of women also agree that it increases their imagination and creativity.

Equal percentage of male participants believe that using substances is a norm in the industry of performing arts.

$48 \%$ of women agree that substances may help them face an audience. This also supports the themes emerging previously. While $42 \%$ men disagree with the same. This shows the difference between the males and females anxiety related to facing audiences while performing, which is a major part of the industry.

The major themes emerging when the participants were asked to elaborate on the effects of substances on their thinking gave out that $32 \%$ said that it did create an alternate state of mind which was hard to achieve without the intake of any substance. 18\% felt that it helped them focus on minute details and increases their awareness. 14\% supported that it 
helped decrease inhibitions on stage and curb stage fright. While $9 \%$ of the participants felt liberated, free and stress free after the intake of a substance.

These themes support the positive expectancy of taking substances by many artists.

Similarly when asked to elaborate on the spontaneous and quick thinking while on stage corresponding themes of dis-inhibition, liberation and an increase in imagination and creativity could be seen. Further themes of promoting quick thinking and spontaneity are added on by $19 \%$ of the participants. A contrary finding also illustrates the slowing down of functioning as reported by $17 \%$ of the sample.

When inquired about their personal experiences of using a substance relief from stress comes out as one of the major outcomes of substance use with $14 \%$ reporting it, with the highest amount of $22 \%$ reporting a feeling of freedom from societal norms. $8 \%$ also reported that it would increase the feel and improvisation of the performance.

A direct question followed asking them about the effect on performance of their use of any substance with $18 \%$ reporting that it helped them connect with themselves and the audience. They also said that they felt more capable of expressing emotions.

The themes thus support the quantitative data wherein a positive expectation of taking a substance is seen in the population. The curbing of anxiety and enhancing emotional experiences have also been brought up.

\section{Perceived link between substance use and creativity}

$28 \%-45 \%$ of the sample thinks that taking a substance before a performance might slightly alter someone's performing skill. $31 \%$ have felt a moderate difference in their performance after the consumption of a substance.
The alteration of skill after the use of a substances was supported by $9 \%$ with effects to increase in energy while $20 \%$ putting forward the effect of an alternate state of mind which helps them see different perspectives and novel openings.

$23 \%$ said that it helped in reducing inhibitions and hence conceiving new ideas and presentations. They also brought out that it increases their concentration which helps them focus better. $17 \%$ also stated that it helps to get into the character which would enhance them to create better roles, designs and productions.

Though 52\% women and $48 \%$ men disagree with substances as positively affecting a person's capability to deal with difficult acts, such as extraordinary lifts in the dance routine, an extremely emotionally heavy scene, a difficult trick/ reaching high notes but as elaborating on these themes such as substances helps in loosening up were given by $14 \%$ with a reduced focus on small mistakes while performing, which helps them to continue the performance on stage without bothering.

$16 \%$ stated that substances would help them to view different perspectives, increasing their imagination and creativity and helping them imagine hidden domains.

$38 \%$ of women have given their response as 2 on the scale of 5 indicating that they perceive or have experienced that a substance would have an effect on their performance more negatively than positively. While $33 \%$ of men seem to be both supporting and negating the difference in performance as they stand at the mid point of 3 on the scale, giving a neutral answer as to their performance can be negatively affected as well as positively enhanced by the intake of a substance. This shows the mixed opinions in the population and also indicates that there is a perception which does not negate the usage of substances for either reducing negative effects or enhancing performance positively. Table 1 shows the perceived reasons given by artists on their usage of substances. 
Table 1 Perceived reasons for Substance Use among Performing Artist

\begin{tabular}{lc}
\hline Perceived reasons for substance use & Percentage of performing artists \\
\hline Increase energy & 31 \\
\hline Relieve pain & 11 \\
\hline Curb appetite & 9 \\
\hline Relieve stress & 61 \\
\hline Lose inhibitions & 39 \\
\hline Get into the character & 35 \\
\hline Enhance spontaneity & 26 \\
\hline Increase efficiency & 20 \\
\hline Increase self-efficacy & 9 \\
\hline Decrease sleep & 10 \\
\hline Other(recreation) & 11
\end{tabular}

Table 2 gives the gender wise distribution of perceived reasons for substance use as reported by performing artists.

$42 \%$ of the respondents said that they won't use any substance in times of extreme practices combined with multiple performances, while $18 \%$ said that their consumption of the preferred substance would increase to several times a day, to deal with the schedule.

$31 \%$ agree that it is a normal thing to use substances in the field of performing arts.

In the sample $57 \%$ tried alcohol after the age of 18 years, also $44 \%$ and $35 \%$ tried cigarettes and cannabis at the same age, respectively.

Table 2-Gender wise reportage of perceived reasons for Substance Use
Teenage has been linked to trial of substances in the general population due to aspects of curiosity and experimentation, as also seen in the sample.

About 5-7\% of the individuals in the sample had faced consequences/were caught in their professional environment for using substances.

$62 \%$ of women tried alcohol after the age of 18 years while $54 \%$ males tried it for the first time at the same age. $38 \%$ women tried cigarettes and marijuana after becoming an adult, while $48 \%$ of men tried it at the same age.

\begin{tabular}{lcc}
\hline Reasons & Females $(\%)$ & Males $(\%)$ \\
\hline Relieve stress & 69 & 60 \\
\hline Lose inhibitions & 52 & 35 \\
\hline Increase energy & 31 & 42 \\
\hline Get into the character & 48 & 31 \\
\hline
\end{tabular}




\section{Current usage and prevalence of substance use in professional performing artists}

Among the participants: In the last one month $25 \%$ of the sample had smoked cigarettes which is a large chunk of the population selected compared to $2.6 \%$ who took alcohol or smoked marijuana. This also indicates at the easy accessibility of cigarettes, along with the acceptability of smoking in the population.

\section{DISCUSSION}

Prior studies have suggested that being in a profession like the literary arts or performing arts is a risk factor for Substance abuse and addiction. (Khantzian, \& Albanese,2008)

There have been inconclusive prior results suggesting that substances can be both positive/negative, affecting creativity and performance.

\section{Prior and Current usage of Substance}

Prior usage of substances or at least some experience with substance use is linked with people's attitudes towards substances, perhaps in a bidirectional manner. In our sample almost $80 \%$ of the participants had tried at least one substance till date. Some of them currently used substances while others had tried it once only. A vast majority of participants (57\%) of artists had tried alcohol at the age of 18 followed by $44 \%$ who tried cigarettes and $35 \%$ who smoked marijuana for the first time. Although a smaller number $(9 \%)$ also tried cocaine and heroin at around 18 years. Alcohol was more popular drug of choice among both men $(54 \%)$ and women $(62 \%)$ but use of cigarettes was lesser for both groups, $48 \%$ and $38 \%$ respectively.

Almost a quarter of the sample were frequent smokers but very few people recently consumed alcohol or marijuana.

\section{Perceived Reasons for Continued Usage}

Stress Relief. Herein we can see the perceived reasons for continued usage of substances as selected by majority of the sample as a relief in stress, stated by $69 \%$ of females and $60 \%$ males in the sample. Recognizing the demands of the field of performing arts stressors such as long and invariable working hours, frequent shows, tiring tours, peer pressure and competition from the internal and overseas developments in the professional arena along with intense auditions and scrutiny by audiences, could be contributing to the continuous usage of substances by artists.

Hectic schedules of about 18-36 hours of work have been reported by almost all the interviewees leading to a decreased amount of sleep, tiredness, fatigue and distress from family.

The eccentric schedules of performing artists as reported are also cited as some of the reasons for the continued usage and even the increase in substance use. 2 of the participants in the interview stated that their intake of cigarettes increased at the time of tight and hectic schedules. Reasons mentioned include to deal with tiredness of the day and feeling calm, increasing number of waking hours, to take a break and to feel happy. Alcohol has also been reported by $10 \%$ of the participants to feel good before a show. While marijuana was also taken by $10 \%$ to relax and generate new ideas in a stressful environment.

The qualitative interviews of 10 participants brought out various stressors in the field. $50 \%$ of them said that it is a hard field to take up in India as it has very less opportunities and exposure in the country. Financial problems are thus, a very common difficulty faced by artists as reported by 8 of the interviewees. The other 2 agree that it had variable and multi income sources and requires you to engage in various activities such as teaching, production, choreography, entrepreneurship, training, etc. simultaneously.

Dealing with family in terms of making them accept performing arts as a profession has also been reported by 7 of the interviewees as a cause of tension. Challenges in terms of family issues relating to finances was also reported by the male interviewees. Similarly the female interviewees expressed that they also face pressure from their families regarding continuing in the profession in terms of being accepted as good daughters in law of the families they marry in. Concerns regarding finding a match for marriage, for a person in the field is reported to be 
difficult due to the instability, as reported by $60 \%$ of female participants.

As seen in the review study done by Heckscher, Albin , Kaplan \& Jenkins in the College Music Symposium,1967 of the book Performing Arts: The Economic Dilemma. A Study of Problems Common to Theatre, Opera, Music and Dance by Baumol\& Bowen 1966 they mentioned that there is no effective way to increase the productivity of live performances and thus as productivity increases the economic wages of other fields would increase, thus, discouraging professional careers in arts as their compensation will not be able to level with the general pars of wages and salaries.

\section{Structural Problems associated with the profession}

Performing artists on an average work for fewer weeks per year, earn considerably less and face higher issues of unemployment than other professionals with equitable educational levels. The median salary of technical workers was reported to be $10 \%$ higher than the median salary of performing artists.(McArthy, Lowell \&Zakarus, 2001)

Physical harm or accidents may take a toll on their career, diseases and ailments may cost them to lose their position in the field and falling short on not having an alternative plan B could be detrimental. American Journal Of Sports Medicine reported Ballet companies to annually state $67-95 \%$, accounting to use of drugs for treatment of trauma, repetitive use and inflammation problems among performers. Weight control and maintenance of lean and lithe bodies is another issue reported by Medicine Science in Sports Exercise,1988, for which drugs are used.

They voiced that there is no surety of taking up an art as a career because it is never seen as a primary profession. Males, seen as the bread winners in the Indian society which operates on patriarchy, feel a lot of pressure in going against societal norms as reported by $50 \%$ of the male participants.

\section{Stress on the body}

Review article exploring the Flexibility in Dance by Deighan\& Martine in 2005, stated that professional standards of Ballet dancers depended upon their bodily flexibility which is a precursor of professional competence in the field, also pointing out the association of this aspect with injury risk and muscular performance. These studies showcase that how physical fitness, especially flexibility in dancers could be a major factor to determine competence related stress in performing arts.

Relieving pain, getting high, experimentation and relaxation were termed as primary motivations of using substances among students (Low \&Gendaszek 2002; McCabe et al. 2007; Quintero et al. 2006; Teteret al. 2005) also used as an aid to pain control, weight loss and sleep (Quintero et al. 2006). Avoidance of stress and momentary pleasure were also reported by $30 \%$ of the participants.

Anxiety sensitivity index was positively correlated with the use of alcohol as a coping strategy along with a positive correlation of nicotine with the same index among females. (Stewart,2002).

\section{Dis-inhibition- influence on performance.}

The qualitative interviews support the data as people reported that their musicality is highly affected by using a substance. Their creativity which a musician termed as his musicality referring to understanding music better, increases. He also mentioned that it helped him disconnect to the world and gave him a feeling and space alone with himself, due to which he could think better. Another respondent reported that he noticed that his brain started functioning faster, he could think faster and differently than usual days. He reported a curb in fear from the audience for which he had performed, making him more confident about himself. About 8 of the interviewees addressed that substances helped them feel at ease with themselves, working on their nervousness and stage fright. It makes them less conscious and they forget the feeling of fear and thus, perform better. 1 of them reported that after taking alcohol he became more engaging and lively on stage and thus, his performance improved. He was appreciated by his bandmates and the audience after the performance.

1 female respondent said that it may help forget the pressure that the audience, mates and managers put on performers. Thus, it helps remain calm in these situations. Another said that it makes a person be himself/herself and hence makes the person happy 
and feel good about oneself. She also added that it will help a performer bare out his/her soul in the performance without thinking of the choreography which is ingrained in them due to multiple practices. She stated that it helps them connect to that part of themselves which gives the feel of the performance.

\section{Perceived link between substance use, Creativity and Performance}

1 male participant also shared an example where he had taken alcohol before a performance to decrease the pain from an injured hand, to play his guitar. He shared that he could then play the guitar for 3 hours at continuation. 1 female participant also reported that as she had a problem being loud on stage, alcohol would help her become more audible. Another shared the experience of a friend who would speak very well on stage after having alcohol, while would stutter and have less fluency otherwise.

The interviewees suggested that they do think that an alternate state of mind is engaged in. Most of them said that it did increase their realm of looking at things, broadened their minds and helps access different domains simultaneously. Another shared that cigarettes helped him create new ideas. Some reported that the brain starts functioning faster and more efficiently with working 4 folds than normal, with a reflexive increase, helping you to see the less travelled path. 2 of them also said that substances help enhance each and every moment of life It thus, has a positive effect on observation, as it also helps slow down things to make them more clear.

An unpublished study by North \&Beauvois obtained complete set of lyrics and dates of drug usage for 5 well known pop groups/artists(namely Aerosmith, The Rolling Stones, The Incredible String Band,The Beatles and the Todd Rundgren.) . Computer analysis of the lyrics indicated that measures of lyrical aggression increased after periods of drug usage, whereas levels of ambivalence, cognitive terms and cooperation decreased after such periods.

Creativity related expectancies influenced creative performance. Performance enhances on creativity tasks for those who expected that the substance would enhance creative functioning. (Hicks, Pederson, Friedman \&McCarthy, 2011) .
The findings of the study are corroborated with empirical data wherein a positive expectancy of using a substance would create a difference in performance. Subjective experiences of this phenomena support the effects on creativity as stated by performers.

\section{CONCLUSION}

Performing arts is a developing field in the current scenario. It has long been linked with entertainment, but has now moved on to establish itself as an independent professional expertise.

Pressures of financial instability, a need for training equivalent to the overseas market, hectic schedules, competitiveenvironments, curbing performance anxiety, delivering to audiences, unemployment, physical strain and lack of family support are some of the difficulties faced by them in the Indian context.

A constant need of creative expression and coping with these various stressors have been cited as some of the reasons for the use of substances in the field of performing arts. Researches have thus, found them at a risk for developing addiction related difficulties.

There has been minimal research in these areas related to substance use, in India. The findings of the study corroborate with previous research findings supporting the positive expectancy of substance use and its effects on creativity and stress relief.

The trends emerging in the study relate to the general attitudes towards use of substances for acceptance in peer groups, experimentation,relief from strain, recreation, along with reasons specific to performing artists, which maintain theses substance related behaviours such as losing inhibitions, increasing imagination and creativity, pain relief, decreasing sleep and maintaining physical appearance. Drugs were also reported to be acceptable in the industry, commonly used for networking and during breaks between rehearsals. It was also seen that there were strong perceptions about positive effects of substances on creativity and performance skill. The reported usage before performance of any substance was negligible, limiting usage to leisure and breaks. 


\section{RECOMMENDATIONS AND FUTURE IMPLICATIONS}

-Alternate interventions for the unique problems faced by artists, curbing the usage of substances . Therapeutic and counselling interventions such as psycho education, about the true effects of substances on their bodies, the shift to substance abuse and its implications on their career.

-Individual and group therapy options can be explored for reasons specific to performing artists. Healthy coping strategies and stress management.

-The current prevalence will help to accurately measure the usage of substances in the sample.

-Statistical associations between substance use, creativity and performance can be explored in further researches.

-Issues faced by performing artists in the Indian Context can be explored in depth in future researches.

\section{LIMITATIONS AND FUTURE STUDY}

-Convenience and snowball sampling were used for the purpose of the study. The same study can be done by using random sampling techniques to make the data more representative.

-Most of the participants of the study belonged to major popular domains of performing arts such as Dance, Theatre and Music. Each form of the performing arts can be further analysed individually using more qualitative analyses.

-A self-developed questionnaire was used to collect the quantitative data. A more qualitative methodology such as interviews or FGDs can enhance our understanding of the issues faced by performing artists.

-The sample was purposive in nature, limiting generalization of results to other samples.

-A descriptive analysis of data was done and no associations have been statistically established among variables. Correlations can be used to find associations between these variables when studied further.
-Subjective experiences of the artists were taken into account for the qualitative analysis. Thus, individual differences and personality factors may have influenced their responses.

In-text lists of references should be listed in chronological order (e.g. author1, 2002, author2, 2004, author3, 2008).Publications by the same author(s) in the same year should be identified with a, b, c (e.g. 2008a, 2008b) closed up to the year.

A reference list should appear at the end ofthe paper under the heading "References". All the references should be arranged in alphabetical order. Please follow the examples below (cf. References).

\section{REFERENCES}

Andrews, J. A., Tildesley, E., Hops, H., \& Li, F. (2002). The influence of peers on young adult substance use. Health psychology, 21(4), 349

Angioi, M., Metsios, G. S., Twichett, E., Koutedakis, Y., \& Wyon, M. (2009). Association between selected physical fitness parameters and aesthetic competence in contemporary dancers. Journal of dance medicine \& science,13(4), 115-123

Basu, D., \& Mattoo, S. K. (1999). Epidemiology of substance abuse in India: methodological issues and future perspectives. Indian journal of psychiatry,41(2), 145.

Batukhtina, E. I., Nevidimova, T. I., Vetlugina, T. P., Kokorina, N. P., \& Bokhan, N. A. (2014). Neurophysiological Patterns of Search and Creative Behavior in Patients with Psychoactive SubstanceInduced Disorders. Bulletin of experimental biology and medicine, 156(5), 598-601.

Baumol, W. J., \& Bowen, W. G. (1993). Performing arts-the economic dilemma: a study of problems common to theater, opera, music and dance. Gregg Revivals.

Bolla, K. I., Brown, K., Eldreth, D., Tate, K., \& Cadet, J. L. (2002). Dose-related neurocognitive effects of marijuana use. Neurology, 59(9), 1337-1343

Deighan, M. A. (2005). Flexibility in dance. Journal of Dance Medicine \& Science, 9(1), 13-17.

Drug Facts: MDMA(Ecstasy or Molly). Date of access:September, 2013, The National Institute of Substance Abuse. The Science of Drug Abuse and Addiction website, http://www.drugabuse.gov/publications/drugfacts/md ma-ecstasy-or-molly

Engs, R. C. (1987). Alcohol and other drugs: selfresponsibility. (Tichenor Pub) 
Evans, A., \& Evans, A. (2013). Secrets of Performing Confidence: For musicians, singers, actors and dancers. (A\&C Black)

Ford, J. A., \& Schroeder, R. D. (2008). Academic strain and non-medical use of prescription stimulants among college students. Deviant Behavior, 30(1), 2653

Freedson, P. (1991). Dictionary of the sport and exercise sciences. Human Kinetics

Green, B., Kavanagh, D., \& Young, R. (2003). Being stoned: a review of self-reported cannabis effects. Drug and alcohol review, 22(4), 453-460

Gupta, S. P., Singh, P., \& Bindal, M. C. (1983). QSAR studies on hallucinogens. Chemical Reviews, 83(6), 633-649

Hansen, P. A., \& Reed, K. (2006). Common musculoskeletal problems in the performing artist. Physical medicine and rehabilitation clinics of North America, 17(4), 789-801.

Healthy Lifestyle Fitness. Date of access: November, 2014, Mayo Clinic website, http://www.mayoclinic.org/healthy-living/fitness/indepth/performance-enhancing-drugs/art-

20046134?pg=2

Hecksher, A., Albin, P.S., Kaplan, M., \& Jenkins.N. (1967). [Review of the book Performing Arts-The Economic Dilemma. A Study of Problems Common to Theater, Opera, Music and Dance, by William J. Baumol, William G. Bowen].College Music Symposium, Vol. 7, pp. 127-142

Hibell, B., Guttomusson, U., Ahlstrom,S., Balakariva,O., Bjarnason, T., Kokkevi,A., \& Kraus, L (2012). The 2011 ESPAD Report-Substance Use among Students in 36 European Countries. The European School Survey Project on Alcohol and Other Drugs(ESPAD). Accessed from http://www.espad.org/uploads/espad_reports/2011/the _2011_espad_report_full_2012_10_29.pdf

Kerr, B., Sheffer, K., Chanbers, C., \& Hallowell, K. (1991). Substance use of creatively talented adults. The Journal of Creative Behavior,25(2), 145-153.

Khantizian, E. J., \& Albanese, M. J. (2008). Understanding addiction as self medication: Finding hope behind the pain. Rowman\& Littlefield Publishers.

Kumar, V., Nehra, D. K., Kumar, P., \& Sunila, G. R. (2013). Prevalence and pattern of substance abuse: a study from de-addiction center. Delhi Psychiatry Journal, 16(1), 110-114.

Lee, S. A. (2001). Adolescent issues in a psychological approach to dancers.Journal of Dance Medicine \& Science, 5(4), 121-126

Livingston. C;(2008) Dictionary of Sport and Exercise Science and Medicine. (Elsevier Limited)
Mccarthy, K. F. (2001). The performing arts in a new era. (Rand Corporation)

Moreh, S. (1992). Live theatre and dramatic literature in the medieval Arab world. (Edinburgh University Press)

Newcomb, M. D., Chou, C. P., Bentler, P. M., \& Huba, G. J. (1988). Cognitive motivations for drug use among adolescents: Longitudinal tests of gender differences and predictors of change in drug use. Journal of Counseling Psychology, 35(4), 426

Noh, Y. E., Morris, T., \& Andersen, M. B. (2009). Occupational stress and coping strategies of professional ballet dancers in Korea. Medical Problems of Performing Artists, 24(3), 124

North, A., \& Hargreaves, D. (2008). The social and applied psychology of music. (Oxford University Press)

Performance Artists and Alprazolam Addiction. Date of access: November,2014 from Alprazolam Addiction Help website, http://www.alprazolamaddictionhelp.com/performanc e-artists-and-alprazolam-addiction

Poczwardowski, A., \& Conroy, D. E. (2002). Coping responses to failure and success among elite athletes and performing artists. Journal of Applied Sport Psychology, 14(4), 313-329

Protecting Children in Families Affected by Substance Use Disorders. Date of access November,2014, from US Department of Health and Human Services website https://www.childwelfare.gov/pubs/usermanuals/subs tanceuse/appendixa.cfm

Rehm, J., Giesbretch, N., Glikman, L., Graham, K., Le, A. D., Mann, R. E.,\& Wells, S. (2011). Addiction Research Centres and the Nurturing of Creativity. Substance abuse research in a modern health care centre: the case of the Centre for Addiction and Mental Health. Addiction, 106(4), 689-697.

Ridout, N. (2006). Stage fright, animals, and other theatrical problems. (Cambridge University Press)

Robins, L. N. (1995). The natural history of substance use as a guide to setting drug policy. American journal of public health, 85(1), 12-13.

Runco, M. A., \& Pritzker, S. R. (Eds.). (1999). Encyclopedia of creativity (Vol. 2). (Elsevier)

Sekulic, D., Kostc, R., \& Miletic, D. (2008). Substance use in dance sport.children, 67.

Sekulic, D., Peric, M., \& Rodek, J. (2010). Substance use and misuse among professional ballet dancers. Substance use \& misuse, 45(9), 1420-1430

Simons, L. K. (1994). The performing arts: a guide to the reference literature. (Libraries Unlimited) 
Stewart, S. H., Karp, J., Pihl, R. O., \& Peterson, R. A. (1997). Anxiety sensitivity and self-reported reasons for drug use. Journal of substance abuse,9, 223-240.

Sullivan, R. J., \& Hagen, E. H. (2002). Psychotropic substance-seeking: evolutionarypathology or adaptation?. Addiction, 97(4), 389-400

The Evolutionary Significance of Psychoactive Drugs. Retrieved November, 2014, from http://swilhite.weebly.com/history-of-psychoactivedrug-use.html
Tolson, G. H. J., \& Cuyjet, M. J. (2007). Jazz and substance abuse: Road to creative genius or pathway to premature death. International journal of law and psychiatry, 30(6), 530-538

Wanke, E. M., Arendt, M., Mitt, H., Koch, F., Davenport, J., Fischer, A., \& Groneberg, D. A. (2014). The theatrical stage as accident site in professional dance. Medical problems of performing artists, 29(1), 32-36

Wood, G. C. (2014). Prevalence, Risk Factors, and Effects of Performance-Related Medical Disorders (PRMD) among Tertiary-trained Jazz Pianists in Australia and the United States. Medical problems of performing artists, 29(1), 37.

Zenic, N., Peric, M., Grcic Zubcevic, N., Ostojic, Z., \& Osttojic, L. (2010). Comparativeanalysis of substance use in ballet, dance sport, and synchronized swimming: results of a longitudinal study. Medical problems of performing artists, 25(2), 75 